\title{
High consistency enzymatic saccharification of sweet sorghum bagasse pretreated with liquid hot water
}

\author{
Wen Wang ${ }^{\mathrm{a}, \mathrm{b}}$, Xinshu Zhuang ${ }^{\mathrm{a}}$, Zhenhong Yuan ${ }^{\mathrm{a}, *}$, Qiang Yu ${ }^{\mathrm{a}}$, Wei Qi ${ }^{\mathrm{a}}$, Qiong Wang ${ }^{\mathrm{a}}$, Xuesong Tan ${ }^{\mathrm{a}}$ \\ ${ }^{a}$ Guangzhou Institute of Energy Conversion, Key Laboratory of Renewable Energy and Gas Hydrate, Chinese Academy of Sciences, Guangzhou 510640, China \\ ${ }^{\mathrm{b}}$ Graduate School of Chinese Academy of Sciences, Beijing 100039, China
}

\section{A R T I C L E I N F O}

\section{Article history:}

Received 8 November 2011

Received in revised form 18 December 2011

Accepted 19 December 2011

Available online 24 December 2011

\section{Keywords:}

Liquid hot water

Sweet sorghum bagasse

Enzymatic saccharification

Ethanol

\begin{abstract}
A B S T R A C T
A laboratory set-up was designed to carry out high consistency enzymatic saccharification of sweet sorghum bagasse (SSB) which was pretreated by liquid hot water (LHW). The effects of two impellers on enzymatic hydrolysis of SSB were investigated. Compared with the double-curved-blade impeller (DCBI), the plate-and-frame impeller (PFI) could improve glucose production by $10 \%$. Tween 80 and fed-batch hydrolysis method adopted in this study produced total sugar of $17.06 \mathrm{~g} / \mathrm{L}$ more than batch hydrolysis and raised the substrate consistency to $30 \%$. At the final substrate loading of $30 \%$, the concentrations of cellobiose, glucose and xylose reached to $15.01 \mathrm{~g} / \mathrm{L}, 88.95 \mathrm{~g} / \mathrm{L}$ and $9.80 \mathrm{~g} / \mathrm{L}$, respectively, and the ethanol concentration reached to $43.36 \mathrm{~g} / \mathrm{L}$ in the case of cellobiose and xylose were not fermented by Saccharomyces cerevisiae Y2034. This study is an attempt at improvement of enzyme hydrolyzing LHW-pretreated material at high consistency.
\end{abstract}

(c) 2011 Published by Elsevier Ltd.

\section{Introduction}

Biofuel originated from lignocellulosic material can be a sustainable alternative fuel for fossil fuel (Farrell et al., 2006). The use of biofuel can reduce greenhouse gas emission, enhance energy security and avoid competing food with human beings (Farrell et al., 2006; Sheehan et al., 2004).

Sweet sorghum, rich of sugars in the juice of stalk, has a great potential as an energy crop (Sipos et al., 2009). It can be adapted to almost all temperate and tropical climates as an annual or short perennial crop and tolerant to high saline and drought conditions to grow in marginal areas (Kim and Day, 2011; Vasilakoglou et al., 2011). The juice from its stalks mainly contains sucrose, fructose and glucose which can be used to produce not only ethanol, but also biodiesel and hydrogen (Wu et al., 2010; Laopaiboon et al., 2009; Gao et al., 2010; Antonopoulou et al., 2011). The leftover stalks after juice extraction are usually used for animal feed, organic manure, co-generation of power and paper making (Sipos et al., 2009). Recently, the stalks or SSB had been evaluated for ethanol production through biochemical conversion (Sipos et al., 2009; Salvi et al., 2010; Li et al., 2010).

The conversion of lignocellulose into ethanol comprises four steps: pretreatment, enzymatic hydrolysis, fermentation and product separation/purification (Taherzadeh and Karimi, 2008). Lignin and hemicellulose connect with cellulose through covalent and

\footnotetext{
* Corresponding author. Tel.: +86 20 87057735; fax: +86 2087057737 .

E-mail address: yuanzh@ms.giec.ac.cn (Z. Yuan).
}

non-covalent bond to form compact structure, which barriers cellulase accessing to cellulose (Alvira et al., 2010). Pretreatment is the key step to affect the yield of fermentable sugar and ethanol for its destruction of the intactness of cell wall. Biological, physical, chemical and physico-chemical pretreatments have been used to break down the compact structure for enhancing enzymes access to the cellulose during hydrolysis step (Mosier et al., 2005; Alvira et al., 2010). Several researches took advantage of several pretreatments on SSB, such as $\mathrm{SO}_{2}$-steam pretreatment (Sipos et al., 2009), dilute ammonia pretreatment (Salvi et al., 2010), ammonia fiber expansion pretreatment (Li et al., 2010), phosphoric acid pretreatment and alkali pretreatment (Goshadrou et al., 2011), and so on, which were proved to be effective for following enzymatic hydrolysis of SSB. But these pretreatments are less environmental friendly than LHW, during which no other chemicals except water need to be added. It generates low concentration of byproduct, has little corrosion on equipment and simplifies substrate handling (Garrote et al., 1999). Although there were several studies reporting enzymatic hydrolysis of LHW-pretreated SSB (Dogaris et al., 2009; Yu et al., 2011a,b), they focused on the optimization and evaluation efficiency of LHW pretreatment. There have been few researches reporting high sugar concentration from enzymatic hydrolysis of LHW-pretreated materials. This study will put attention on enhancing hydrolytic efficiency of LHW-pretreated SSB.

At high substrate consistency, enzymatic hydrolysis of LHWpretreated SSB could not give high sugar concentration. In order to solve this problem, non-ion surfactant which was reported to enhance enzymatic saccharification was used in this study 
(Eriksson et al., 2002). It could adsorb lignin through hydrophobic interaction to prevent unproductive binding of enzymes to lignin (Eriksson et al., 2002). Furthermore, in order to attain high sugar concentration, a laboratory set-up was designed to do this experiment, which would provide useful data for industrial application.

\section{Methods}

\subsection{Raw material, chemicals and pretreatment}

Sweet sorghum bagasse, the solid residue left after solid-state ethanol fermentation, was provided by Beijing Tai Tian Di Energy Technology Development Co. Ltd. It was milled and screened through $40-60$ mesh sieves, then washed and dried at $105^{\circ} \mathrm{C}$ to a constant weight.

Cellulase, with activities of $888 \mathrm{FPU} / \mathrm{g}$ soluble protein, produced from Penicillium sp. and mixed with small quantities of other enzymes such as xylanase, was bought from Imperial Jade Biotechnology Co. Ltd. (China).

LHW pretreatment was conducted at the condition of $180^{\circ} \mathrm{C}$, $4.0 \mathrm{MPa}, 500 \mathrm{rpm}$ for $20 \mathrm{~min}$ with laboratory facility. The ratio of deionized water to SSB is 20:1 (Yu et al., 2010). After pretreatment, the temperature was cooled down to less than $140{ }^{\circ} \mathrm{C}$ by cold water. When the temperature dropped to room temperature, the pretreated SSB was taken out and dried at $105^{\circ} \mathrm{C}$ to a constant weight. After drying, the pretreated material was ground to more than 100 mesh by swing pulverizer, then stored in a desiccator at room temperature.

\subsection{Enzymatic hydrolytic facility}

A set of facility was designed for enzymatic hydrolysis of the LHW-pretreated materials. The setup consists of a control system, a 30-L heating tank and a 1-L hydrolytic reactor. All parts are made of $316 \mathrm{~L}$ stainless steel. Through control system, the rotation speed of impeller can be adjusted from 10 to $300 \mathrm{rpm}$ and the temperature can be set from room temperature to $100^{\circ} \mathrm{C}$. The heating tank is used to heat water which is pumped to the jacket to keep the temperature of the hydrolytic reactor at a setting value. The hydrolyzing reaction is conducted in the hydrolytic reactor. Two sets of different impellers are designed (Fig. 1), one is plate-and-frame impeller (PFI) and the other is double-curved-blade impeller

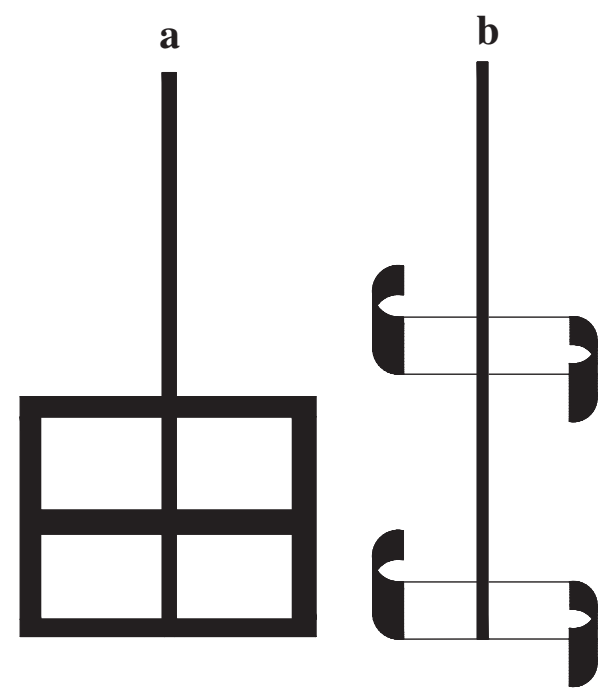

Fig. 1. Scheme of two impellers, (a) plate-and-frame impeller (PFI); (b) doublecurved-blade impeller (DCBI).
(DCBI). The speeds of PFI and DCBI were investigated for their effects on enzymatic hydrolysis of LHW-pretreated SSB. The experiment is carried out as following: all the feed stocks including pretreated substrate, $0.05 \mathrm{M}$ sodium acetate buffer (pH4.8) and cellulase are put into the reactor, and then the cover is sealed. The hydrolytic reactor is heated to $50{ }^{\circ} \mathrm{C}$ and the feed stocks are mixed with impellers at a setting speed.

\subsection{Enzymatic hydrolysis}

The pretreated SSB and 0.05 M sodium acetate buffer ( $\mathrm{pH} 4.8$ ) were mixed into the reactor to form $20 \%(\mathrm{w} / \mathrm{v})$ solid concentration. The experiment was performed at $50{ }^{\circ} \mathrm{C}$ loading with $20 \mathrm{FPU} / \mathrm{g}$ glucan cellulase and $0.175 \mathrm{~mL} / \mathrm{g}$ dried material Tween 80 which was determined based on previous study (Under review). 72-h enzymatic hydrolysis conducted at the speeds of $50 \mathrm{rpm}, 100 \mathrm{rpm}$ and $150 \mathrm{rpm}$ for PFI and DCBI was to choose the optimum impeller and speed for obtaining higher sugar concentration. 120-h enzymatic hydrolysis at optimum speed with optimum impeller was carried out for batch hydrolysis. Samples were taken at $12 \mathrm{~h}$, 24 h, 36 h, 48 h, 60 h, 72 h, 84 h, 96 h, 108 h and 120 h for analysis.

For fed-batch enzymatic hydrolysis, the initial loading of pretreated SSB was half of the final loading. Then half of the initial loading of pretreated SSB was fed to the enzymatic hydrolysis system at $24 \mathrm{~h}$ and $48 \mathrm{~h}$ to make the final solid loadings reach to $15 \%$, $20 \%$ and $30 \%$, respectively. Simultaneously, cellulase was fed in with $20 \mathrm{FPU} / \mathrm{g}$ glucan and $30 \mathrm{FPU} / \mathrm{g}$ glucan, respectively and Tween 80 was $0.175 \mathrm{~mL} / \mathrm{g}$ dried material. The reaction was performed at $50{ }^{\circ} \mathrm{C}$ for $120 \mathrm{~h}$ at the optimum speed with optimum impeller.

\subsection{Fermentation}

Saccharomyces cerevisiae Y2034 was bought from National Center for Agricultural Utilization Research. To prepare the inoculum of S. cerevisiae Y2034, a loopful of cells were added to each 15$\mathrm{mL}$ test tube containing $5 \mathrm{~mL}$ sterile YPD medium consisting of glucose, peptone and yeast extract at concentrations of 20,20, and $10 \mathrm{~g} / \mathrm{L}$, respectively. The test tubes were incubated in a rotary shaker at $30^{\circ} \mathrm{C}$ and $150 \mathrm{rpm}$ for $24 \mathrm{~h}$. At the end of incubation, the contents of these tubes were aseptically centrifuged and used for fermentation. $0.04 \%$ (wet weight/volume) of S. cerevisiae Y2034 was inoculated into $250-\mathrm{mL}$ Erlenmeyer flask containing enzymatic hydrolysate with the addition of $5 \mathrm{~g} / \mathrm{L}$ yeast extract, $5 \mathrm{~g} / \mathrm{L}$ peptone, $5 \mathrm{~g} / \mathrm{L} \mathrm{KH}_{2} \mathrm{PO}_{4}, 0.2 \mathrm{~g} / \mathrm{L}\left(\mathrm{NH}_{4}\right)_{2} \mathrm{SO}_{4}$ and $0.4 \mathrm{~g} / \mathrm{L} \mathrm{MgSO}{ }_{4} \cdot 7 \mathrm{H}_{2} \mathrm{O}$. All the fermentations were performed at $30^{\circ} \mathrm{C}, 150 \mathrm{rpm}$ for $72 \mathrm{~h}$. Samples were taken at $0 \mathrm{~h}, 12 \mathrm{~h}, 24 \mathrm{~h}, 36 \mathrm{~h}, 48 \mathrm{~h}, 60 \mathrm{~h}$ and $72 \mathrm{~h}$ for analysis of yield of ethanol and consumption of sugars.

\subsection{Analytical methods and calculations}

Cellulase activity was assayed on filter paper by the standard IUPAC method (Ghost, 1987). Composition analyses of the raw material, the pretreated substrate and the enzymatic hydrolyzed residue were carried out following a National Renewable Energy Laboratory (NREL) analytical procedure (Sluiter et al., 2008). Hydrolyzed and fermented samples were centrifugated at $12,000 \mathrm{rpm}$ for $2 \mathrm{~min}$ by a centrifuge (Eppendorf 5417R). The supernatants were used for analysis of sugar and ethanol contents, respectively. Sugar concentrations were analyzed by HPLC (Waters 2695) equipped with a RI 2414 refractive index detector and a Shodex sugar $\mathrm{SH}-1011$ column. The mobile phase is $5 \mathrm{mmol} / \mathrm{L} \mathrm{H}_{2} \mathrm{SO}_{4}$ at a flow rate of $0.5 \mathrm{~mL} / \mathrm{min}$ at $50^{\circ} \mathrm{C}$.

Ethanol concentrations were determined using a gas chromatograph of Agilgent HP 6820 with a capillary column $(30.0 \mathrm{~m} \times 0.25 \mathrm{~mm} \times 0.25 \mu \mathrm{m})$ and a flame ionization detector 
(GC-FID, $250^{\circ} \mathrm{C}$ ). Operating conditions are: injector at $250^{\circ} \mathrm{C}$, nitrogen as the carrier gas at the flow rate of $30 \mathrm{~mL} / \mathrm{min}$, and split ratio of $1: 50$. Sample volume is $0.4 \mu \mathrm{L}$. Initially, the sample is held at $160{ }^{\circ} \mathrm{C}$ for $1.4 \mathrm{~min}$ then the temperature is increased to $200^{\circ} \mathrm{C}$ at the rate of $25^{\circ} \mathrm{C} / \mathrm{min}$ and held for $2 \mathrm{~min}$. The total sample run time is $6.4 \mathrm{~min}$.

The conversion efficiency of glycan $(\zeta)$ is defined as the ratio of total pentose and hexose recovered from enzymatic hydrolysis to the total amount of theoretical sugars in the pretreated solid substrate:

$\zeta=\left(1-\frac{m_{h r} \eta_{h g}+m_{h r} \eta_{h x}}{m_{p s} \eta_{p g}+m_{p s} \eta_{p x}}\right) \times 100$

$m_{h r}$ and $m_{p s}$ are the mass of the enzymatic hydrolyzed residue and pretreated solid substrate, respectively (g). $\eta_{h g}$ and $\eta_{p g}$ are the mass ratio of glucan to enzymatic hydrolyzed residue and pretreated solid substrate. $\eta_{h x}$ and $\eta_{p x}$ are the mass ratio of xylan to enzymatic hydrolyzed residue and pretreated solid substrate.

The percentage theoretical ethanol yield was calculated as followings (Salvi et al., 2010):

$$
\begin{aligned}
\% \text { Theoretical Ethanol Yield }= & \frac{[\text { EtOH }]}{0.51 \times(1.11 \times f \times[\text { Biomass }])} \\
& \times 100 \%
\end{aligned}
$$

[EtOH] is the ethanol amount in the fermentation broth $(\mathrm{g} / \mathrm{L})$. [Biomass] is the initial SSB (dry weight) for fermentation. $f$ is the cellulose fraction of the SSB. 0.51 is the conversion factor for glucose to ethanol based on stoichiometric biochemistry of yeast, and 1.11 is the conversion factor of cellulose to equivalent glucose. All of the analytical tests were performed in duplicate.

\section{Results and discussion}

3.1. Compositions of the raw feedstock, pretreated substrate, and hydrolyzed residue of SSB

Table 1 summarizes the compositions of untreated, pretreated and hydrolyzed SSB. After LHW pretreatment, 74.81\% xylan and $31.91 \%$ lignin are removed and $100 \%$ glucan is recovered from the raw SSB, which indicates that the LHW-pretreated process could dissolve most of hemicellulose and part of lignin. This is consistent with the results of other researches (Mok and Antal, 1992; Yu et al., 2010). Compared with hemicellulose, lignin is more remarkable to hinder enzymatic hydrolysis (Várnai et al., 2010). Meanwhile, the main compositions of LHW-pretreated SSB are lignin and cellulose, which indicates that the inhibition effect of lignin on enzymatic hydrolysis is obvious (Zhu et al., 2008). In order to reduce the negative effect of lignin, Tween80, a nonionic surfactant, which had been proved to adsorb lignin to improve enzymatic hydrolysis of lignocellulose, was applied (Eriksson et al., 2002).

In Table 1, it can be found out that the conversion of glucan goes up with the loading of cellulase increasing at the same substrate concentration. When the cellulase loading increases from 20 to $30 \mathrm{FPU} / \mathrm{g}$ glucan, the cellulose conversions increase by $8.54 \%$ and $13.85 \%$, respectively, for $15 \%$ and $20 \%$ substrate loadings. As expected, the cellulose conversion decreases with solid concentration increasing under the condition of a given cellulase loading. Similar trend is also observed for xylan conversion as the enzyme cocktail also containing hemicellulase. LHW pretreatment combining with enzymatic hydrolysis can remove nearly $90 \%$ xylan, which facilitates enzymatic hydrolysis of the cellulose. However, the quantity of lignin should be constant, because there are no laccase or other enzymes existing in the cellulase to degrade lignin during the process of enzymatic hydrolysis. As expected, the amounts of lignin remained in the hydrolytic residues are approximately the same as pretreated SSB.

\subsection{Effect of mixing speed on enzymatic hydrolysis}

The effect of stirring speed of the both impellers on enzymatic hydrolysis is studied (Fig. 2). It is found that maximum sugar concentration is obtained at $100 \mathrm{rpm}$ for 72 -h hydrolysis with both impellers. The total sugar concentration produced by PFI is approximately $17.9 \%$ higher than that by DCBI, which might be caused by the stirring pattern. At first, due to high solid concentration, there is only axial flow for DCBI and PFI. With the enzymatic hydrolysis proceeding, the viscosity of solution goes down and radial flow comes forth. When the solid is liquefied to a certain degree, the solution flows fluently, and thus the axial flow is disappeared and only radial flow exists in the later hydrolysis. As for DCBI,

Table 1

\begin{tabular}{|c|c|c|c|c|c|c|c|c|c|c|c|c|}
\hline \multirow[t]{2}{*}{ Samples } & \multirow{2}{*}{$\begin{array}{l}\text { Solid } \\
\text { remain } \\
(\%)^{a}\end{array}$} & \multicolumn{4}{|c|}{ Glucan (\%) } & \multicolumn{4}{|c|}{ Xylan (\%) } & \multicolumn{3}{|c|}{ Acid-insoluble lignin and ash (\%) } \\
\hline & & Content & $\begin{array}{l}\text { Yield }(\mathrm{g} / \\
100 \mathrm{~g} \\
\text { raw } \\
\mathrm{SSB})^{\mathrm{b}}\end{array}$ & $\begin{array}{l}\text { Yield }(\mathrm{g} / \\
100 \mathrm{~g} \\
\text { pretreated } \\
\text { SSB })^{\mathrm{c}}\end{array}$ & $\begin{array}{l}\text { Enzymatic } \\
\text { hydrolysis } \\
\text { conversion } \\
\text { efficiency }^{\mathrm{d}}\end{array}$ & Content & $\begin{array}{l}\text { Yield }(\mathrm{g} / \\
100 \mathrm{~g} \\
\text { raw } \\
\mathrm{SSB})^{\mathrm{b}}\end{array}$ & $\begin{array}{l}\text { Yield }(\mathrm{g} / \\
100 \mathrm{~g} \\
\text { pretreated } \\
\text { SSB })^{\mathrm{c}}\end{array}$ & $\begin{array}{l}\text { Enzymatic } \\
\text { hydrolysis } \\
\text { conversion } \\
\text { efficiency }^{\text {d }}\end{array}$ & Content & $\begin{array}{l}\text { Yield (g/ } \\
100 \mathrm{~g} \\
\text { raw SSB) } \\
\text { b }\end{array}$ & $\begin{array}{l}\text { Yield }(\mathrm{g} / \\
100 \mathrm{~g} \\
\text { pretreated } \\
\text { SSB })^{\mathrm{c}}\end{array}$ \\
\hline Raw SSB & 100 & 39.79 & & & & 20.80 & & & & 23.47 & & \\
\hline $\begin{array}{l}\text { Pretreated } \\
\text { SSB }\end{array}$ & 64.09 & 62.17 & 39.85 & & & 8.18 & 5.24 & & & 24.93 & 15.98 & \\
\hline $\begin{array}{c}\text { Residue } \\
\mathrm{A}^{\mathrm{e}}\end{array}$ & 41.12 & 47.78 & 19.64 & 30.66 & 50.70 & 5.46 & 2.25 & 3.50 & 57.21 & 43.28 & 17.80 & 27.77 \\
\hline $\begin{array}{c}\text { Residue } \\
\mathrm{B}^{\mathrm{e}}\end{array}$ & 37.12 & 43.75 & 16.24 & 25.34 & 59.24 & 4.86 & 1.80 & 2.82 & 65.53 & 42.85 & 15.91 & 24.82 \\
\hline $\begin{array}{c}\text { Residue } \\
\mathrm{C}^{\mathrm{e}}\end{array}$ & 43.88 & 49.23 & 21.60 & 33.71 & 45.78 & 5.08 & 2.23 & 3.48 & 57.46 & 41.27 & 18.11 & 28.25 \\
\hline $\begin{array}{c}\text { Residue } \\
\mathrm{D}^{\mathrm{e}}\end{array}$ & 36.62 & 43.93 & 16.09 & 25.10 & 59.63 & 4.49 & 1.64 & 2.57 & 68.58 & 41.49 & 15.19 & 23.71 \\
\hline Residue $\mathrm{E}^{\mathrm{e}}$ & 38.57 & 47.34 & 18.26 & 28.49 & 54.17 & 4.88 & 1.88 & 2.93 & 64.18 & 41.31 & 15.93 & 24.86 \\
\hline
\end{tabular}

Compositions of raw SSB, pretreated SSB and the enzymatic hydrolyzed residues at different solid and cellulase loadings.

a (Mass of raw SSB- mass of pretreated or hydrolyzed SSB)/mass of raw SSB $\times 100 \%$.

b Percent of ingredients contained in its own solid $\times$ its solid remain.

c Percent of ingredients contained in hydrolyzed residues $\times$ (mass of hydrolyzed residues/mass of pretreated SSB).

d (Mass of ingredients contained in pretreated SSB- mass of ingredients contained in hydrolyzed residues)/mass of ingredients contained in pretreated SSB.

e Note: A: $15 \%$ solid concentration, $20 \mathrm{FPU} / \mathrm{g}$ glucan of cellulase loading; B: $15 \%$ solid concentration, $30 \mathrm{FPU} / \mathrm{g}$ glucan of cellulase loading; C: $20 \%$ solid concentration,

$20 \mathrm{FPU} / \mathrm{g}$ glucan of cellulase loading; D: $20 \%$ solid concentration, $30 \mathrm{FPU} / \mathrm{g}$ glucan of cellulase loading; E: $30 \%$ solid concentration, $30 \mathrm{FPU} / \mathrm{g}$ glucan of cellulase loading. 


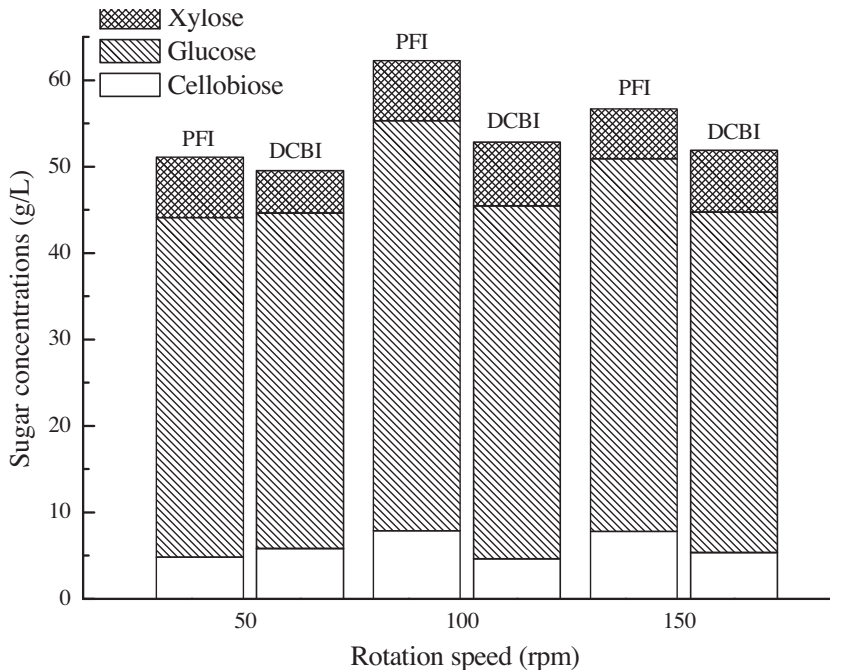

Fig. 2. Comparison of enzymatic hydrolyzing effect with two kinds of impellers at different rotation speeds.

the layer of solution which locates at the same level with blade can be stirred more intensively than other layers. But for PFI, every layer of solution has the same stirring intensity, which is better for mixing solution and leads to the total sugar concentration higher than that of DCBI. In addition, the total sugar concentrations produced at the speed of $50 \mathrm{rpm}$ and $150 \mathrm{rpm}$ are lower than that of $100 \mathrm{rpm}$. Several researches demonstrated that the adsorption of cellulase to cellulose was not completely reversible (Nidetzky et al., 1994; Henrissat, 1994). Nidetzky et al. (1994) also pointed out that re-adsorption of desorbed free cellulase in the hydrolysate could take place. The mixing speed certainly affects this re-adsorption process. The results show that maximum yield of sugar is achieved at $100 \mathrm{rpm}$.

\subsection{Effect of washing substrate on enzymatic hydrolysis}

In the process of LHW pretreatment, several by-products like furfural, 5-hydroxymethylfurfural, formic acid, etc. would be produced, and these materials could inhibit enzymatic activity and growth of yeast (Yu et al., 2010; Jørgensen et al., 2007). Generally, it is recognized that to wash the pretreated substrate can remove inhibitors to improve the enzymatic hydrolysis and obtain much more sugars. But to wash substrate will complex the process, consume large amount of water thus be negative for the process to be economical.

The yields of total sugar from enzymatic hydrolysis using the washed and unwashed LHW-pretreated SSB are compared at $20 \%$ solid loading. The contents of xylose, arabinose, furfural, and formic acid in the pretreated solution are $0.499 \mathrm{~g} / \mathrm{L}, 0.299 \mathrm{~g} / \mathrm{L}$, $0.313 \mathrm{~g} / \mathrm{L}$ and $0.142 \mathrm{~g} / \mathrm{L}$, respectively. Glucose and 5-hydroxymethylfurfural were not detected with HPLC. Most of degradation products dissolve in the solution and few are contained in the pretreated SSB, which indicates that inhibition from degradation products will be insignificant for enzymatic hydrolytic washed and unwashed pretreated SSB. In Fig. 3, it can be seen that the final sugar concentrations of unwashed and washed substrate are $66.09 \mathrm{~g} / \mathrm{L}$ and $63.19 \mathrm{~g} / \mathrm{L}$, respectively, which suggests that the concentrations of byproducts produced during the process of LHW pretreatment are too low to hinder the enzymatic hydrolysis in this study. The reason that the sugar concentration of washed pretreated SSB is lower than the unwashed one may be ascribed to that the washing process might wash off the tiny cellulose particles which are very easy to be hydrolyzed into sugars. It can be deduced
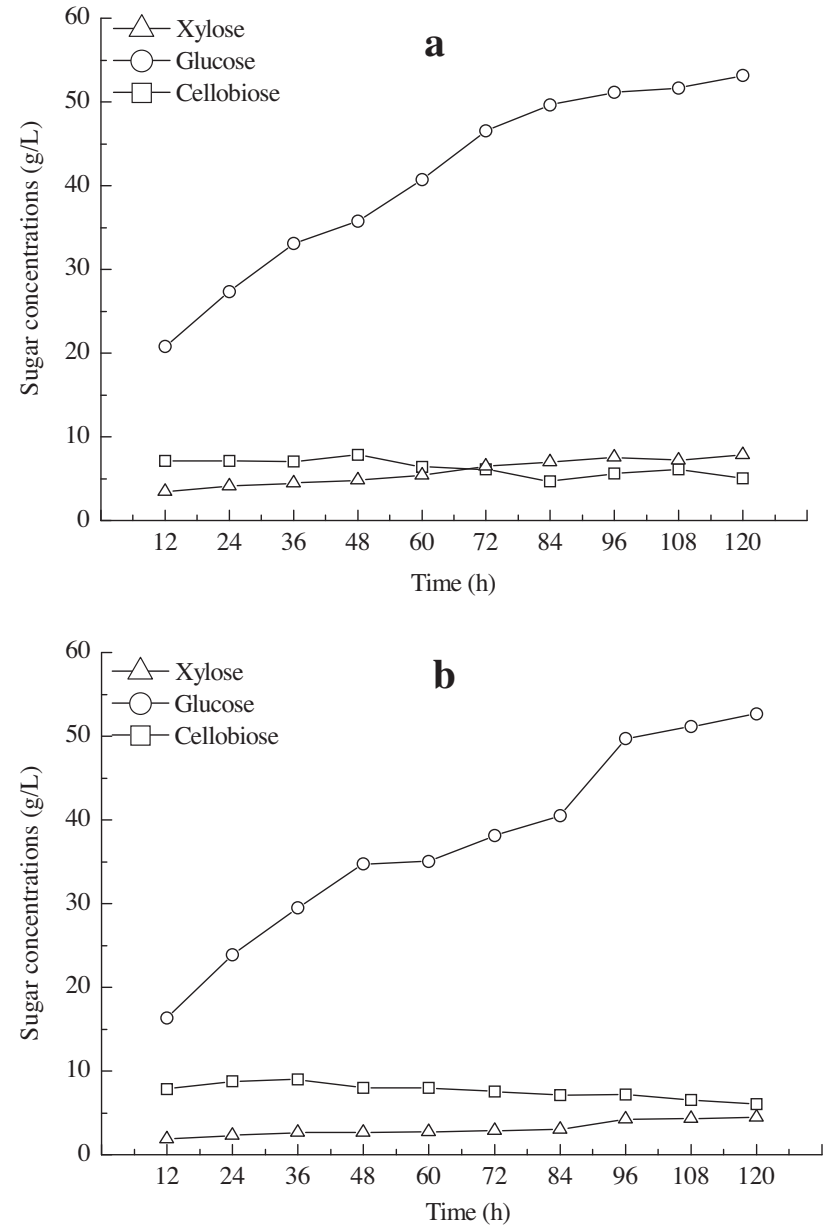

Fig. 3. Comparison of sugar concentrations between unwashed and washed pretreated SSB, (a) unwashed pretreated SSB; (b) washed pretreated SSB.

that the LHW-pretreated SSB can be hydrolyzed by cellulase directly without washing. After hydrolyzing for $96 \mathrm{~h}$, the sugar concentration increased inconspicuously, which might be affected by the high sugar concentration and lignin content. High sugar concentration will result in feedback inhibition to lower the cellulase activity. In addition, with the enzymatic hydrolysis proceeding, the cellulose content of the substrate is reduced, which leads to the increase of relative content of lignin, so the interaction between cellulase and lignin rises up. The effective cellulase participated in hydrolysis process will go down.

\subsection{Comparison of batch and fed-batch hydrolysis}

In fed-batch hydrolysis, the initial substrate is first liquefied by starting with a low solid loading before next feeding to maintain a low viscosity of the system throughout the hydrolysis process. As a result, it is expected that fed-batch process can give better hydrolytic efficiency than batch process at the same final solid loading. The final concentrations of cellobiose, glucose and xylose obtained from batch hydrolysis (Fig. 3a) are $5.07 \mathrm{~g} / \mathrm{L}, 53.17 \mathrm{~g} / \mathrm{L}$ and $7.85 \mathrm{~g} / \mathrm{L}$, respectively, which are lower than those of fed-batch hydrolysis for final solid loading of 20\% (7.78 g/L cellobiose, $65.99 \mathrm{~g} / \mathrm{L}$ glucose and $9.38 \mathrm{~g} / \mathrm{L}$ xylose, Fig. 4C).

In this study, fed-batch hydrolysis of pretreated SSB was conducted at the solid concentrations of $15 \%, 20 \%, 30 \%$ and the cellulase loadings of $20 \mathrm{FPU} / \mathrm{g}$ glucan and $30 \mathrm{FPU} / \mathrm{g}$ glucan. At the same solid concentration, high cellulase loading gives high sugar 


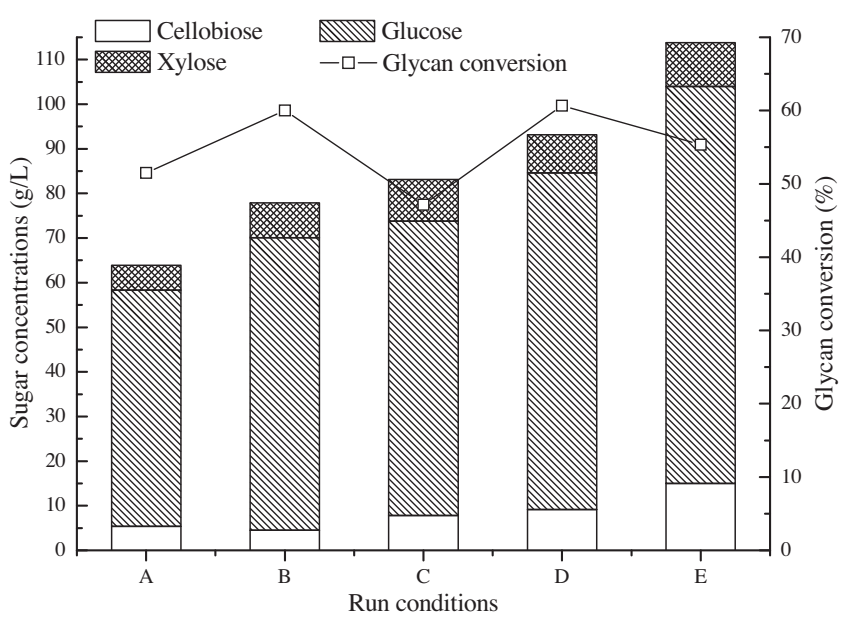

Fig. 4. Sugar concentrations and glycan conversion after 120 -h fed-batch enzymatic hydrolysis of LHW-pretreated SSB at different solid concentrations and cellulase loadings, A, B, C, D and E are the same as Table 1.

concentrations (Fig. 4A and B; C and D). The cellobiose, glucose and xylose concentrations of $15.01 \mathrm{~g} / \mathrm{L}, 88.95 \mathrm{~g} / \mathrm{L}$ and $9.80 \mathrm{~g} / \mathrm{L}$, respectively are achieved at 30\% final solid loading with $30 \mathrm{FPU} / \mathrm{g}$ glucan loadings of cellulase. From Fig. 4, it can be seen that at the same cellulase loading, the glycan conversion efficiency of low solid concentration is higher than that of high solid concentration (Fig. 4A and $\mathrm{C} ; \mathrm{B}, \mathrm{D}$ and $\mathrm{E}$ ), while at the same solid concentration, the glycan conversion efficiency of high cellulase loading is higher than that of low cellulase loading (Fig. 4A and B; C and D), which is consist with expectation (higher glycan conversion efficiency from low solid concentration).
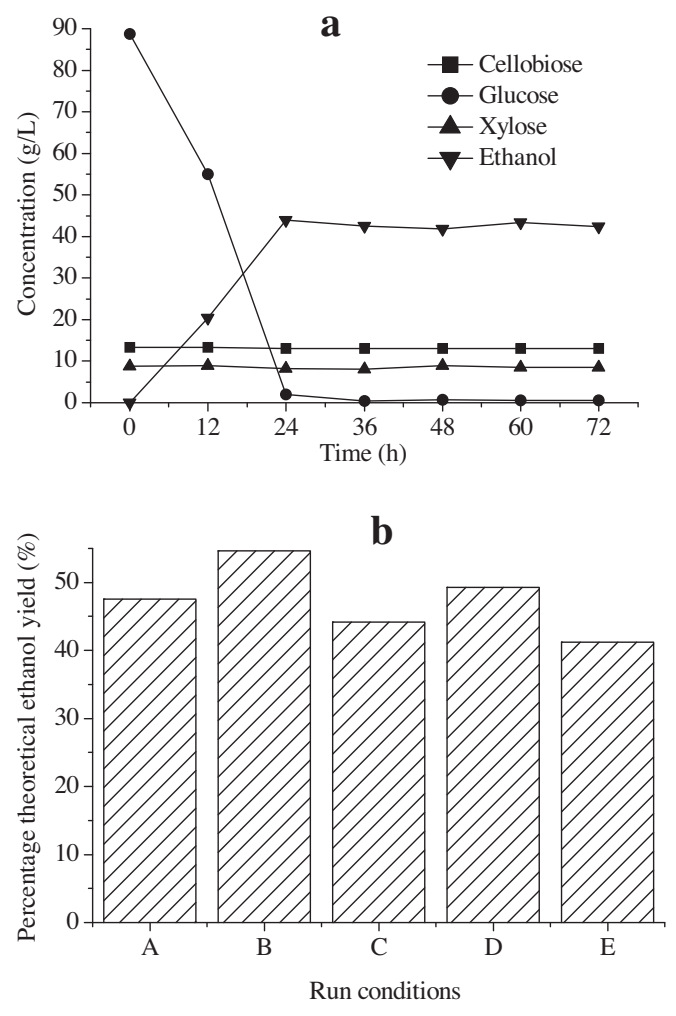

Fig. 5. Fermentation of hydrolysate of run condition $E$ (a) and yield of ethanol compared with the theoretic ethanol yield (b), A-E are the same as Table 1.
The small difference in glycan conversion efficiency between $\mathrm{B}$ and D (Fig. 4) suggests that the cellulase loading of $30 \mathrm{FPU} / \mathrm{g}$ glucan is more suitable for $20 \%$ final solid concentration of LHW-pretreated SSB in fed-batch hydrolysis than $15 \%$ final solid concentration to obtain higher sugar concentration. Solid loading can be increased to $30 \%$ without sacrificing glycan conversion efficiency at this cellulase loading. The highest glycan conversion efficiency for run condition B is $60.68 \%$ which is only $5.33 \%$ more than that achieved at $30 \%$ solid loading.

\subsection{Fermentation}

The hydrolyzates obtained from fed-batch hydrolysis were fermented by S. cerevisiae Y2034. As shown in Fig. 5, the glucose concentration decreases with time rapidly. The concentrations of cellobiose and xylose remain unchanged, which suggests that Y2034 cannot make use of cellobiose and xylose as carbon sources. At the beginning of 24-h fermentation, glucose is used up and the concentration of ethanol achieves the top, which implies that the fermentation of Y2034 is very efficient. The concentration of ethanol depends on the concentration of glucose. High concentration of glucose gives high concentration of ethanol. The highest concentration of ethanol reached in this work is $43.36 \mathrm{~g} / \mathrm{L}$ (Fig. 5a). From Fig. 5b, low solid concentration produces higher percentage theoretical ethanol yield ( $A$ and $C$; B, D and $E$ ), and high cellulase loading gives higher percentage theoretical ethanol yield ( $A$ and $B$; $C$ and $\mathrm{D})$. The highest percentage theoretical ethanol yield is $54.62 \%$ (B).

\section{Conclusions}

The condition that the PFI rotated at the speed of $100 \mathrm{rpm}$ is appropriate for enzymatic hydrolysis. The process of washing pretreated SSB cannot enhance enzymatic hydrolysis obviously. Fedbatch hydrolysis can achieve higher sugar concentration than batch hydrolysis, and make the solid concentration up to $30 \%$. Higher solid loading gives higher sugar concentration, but lower glycan conversion efficiency. Higher cellulase loading produces not only higher sugar concentration, but also higher glycan conversion efficiency and yield of ethanol. This setup is suitable for hydrolyzing high solid concentration when the cellulase loading was high and set an example to industrial application.

\section{Acknowledgements}

Thank Doctor Zhu Junyong from Forest Products Laboratory for modifying and advising this paper. This work was supported financially by the Natural Science Foundation of China (51176196), the National Key Technology R\&D Program (No. 2011BAD22B01) and the National High Technology Research and Development Program of China (2010AA101606).

\section{References}

Alvira, P., Tomás-Pejó, E., Ballesteros, M., Negro, M.J., 2010. Pretreatment technologies for an efficient bioethanol production process based on enzymatic hydrolysis: a review. Bioresour. Technol. 101, 4851-4861.

Antonopoulou, G., Gavala, H.N., Skiadas, I.V., Lyberatos, G., 2011. Effect of substrate concentration on fermentative hydrogen production from sweet sorghum extract. Int. J. Hydrogen Energy 36, 4843-4851.

Dogaris, I., Karapati, S., Mamma, D., Kalogeris, E., Kekos, D., 2009. Hydrotherma processing and enzymatic hydrolysis of sorghum bagasse for fermentable carbohydrates production. Bioresour. Technol. 100, 6543-6549.

Eriksson, T., Börjesson, J., Tjerneld, F., 2002. Mechanism of surfactant effect in enzymatic hydrolysis of lignocellulose. Enzyme Microb. Technol. 31, 353-364.

Farrell, A.E., Plevin, R.J., Turner, B.T., Jones, A.D., O'Hare, M., Kammen, D.M., 2006. Ethanol can contribute to energy and environmental goals. Science 311, 506508. 
Gao, C., Zhai, Y., Ding, Y., Wu, Q., 2010. Application of sweet sorghum for biodiesel production by heterotrophic microalga Chlorella protothecoides. Appl. Energy 87 756-761.

Garrote, G., Domínguez, H., Parajó, J.C., 1999. Hydrothermal processing of lignocellulosic materials. Holz Roh Werkst. 57, 191-202.

Ghost, T.K., 1987. Measurement of cellulose activities. Pure Appl. Chem. 59, 257268.

Goshadrou, A., Karimi, K., Taherzadeh, M.J., 2011. Bioethanol production from sweet sorghum bagasse by Mucor hiemalis. Ind. Crops Prod. 34, 1219-1225.

Henrissat, B., 1994. Cellulases and their interaction with cellulose. Cellulose 1, 169196.

Jørgensen, H., Kristensen, J.B., Felby, C., 2007. Enzymatic conversion of lignocellulose into fermentable sugars: challenges and opportunities. Biofuels, Bioprod. Biorefin. 1, 119-134.

Kim, M., Day, D.F., 2011. Composition of sugar cane, energy cane, and sweet sorghum suitable for ethanol production at Louisiana sugar mills. J. Ind. Microbiol. Biotechnol. 38, 803-807.

Laopaiboon, L., Nuanpeng, S., Srinophakun, P., Klanrit, P., Laopaiboon, P., 2009 Ethanol production from sweet sorghum juice using very high gravity technology: effects of carbon and nitrogen supplementations. Bioresour. Technol. 100, 4176-4182.

Li, B., Balan, V., Yuan, Y., Dale, B.E., 2010. Process optimization to convert forage and sweet sorghum bagasse to ethanol based on ammonia fiber expansion (AFEX) pretreatment. Bioresour. Technol. 101, 1285-1292.

Mok, W.S.-L., Antal, M.J.Jr., 1992. Uncatalyzed solvolysis of whole biomass hemicellulose by hot compressed liquid water. Ind. Eng. Chem. Res. 31, 11571161.

Mosier, N., Wyman, C.E., Dale, B.D., Elander, R.T., Lee, Y.Y., Holtzapple, M., Ladisch, C.M., 2005. Features of promising technologies for pretreatment of lignocellulosic biomass. Bioresour. Technol. 96, 673-686.

Nidetzky, B., Steiner, W., Claeyssens, M., 1994. Cellulose hydrolysis by the cellulases from Trichoderma reesei: adsorptions of two cellobiohydrolases, two endocellulases and their core proteins on filter paper and their relation to hydrolysis. Biochem. J. 303, 817-823.

Salvi, D.A., Aita, G.M., Robert, D., Bazan, V., 2010. Ethanol production from sorghum by a dilute ammonia pretreatment. J. Ind. Microbiol. Biotechnol. 37, 27-34.
Sheehan, J., Aden, A., Paustian, K., Killian, K., Brenner, J., Walsh, M., Nelson, R., 2004. Energy and environmental aspects of using corn stover for fuel ethanol. J. Ind. Ecol. 7, 117-146.

Sipos, B., Réczey, J., Somorai, Z., Kádár, Z., Dienes, D., Réczey, K., 2009. Sweet sorghum as feedstock for ethanol production: enzymatic hydrolysis of steampretreated bagasse. Appl. Biochem. Biotechnol. 153, 151-162.

Sluiter, A., Hames, B., Ruiz, R., Scarlata, C., Sluiter, J., Templeton, D., Crocker, D., 2008. Determination of structural carbohydrates and lignin in biomass. Technical Report NREL/TP-510-42618.

Taherzadeh, M.J., Karimi, K., 2008. Pretreatment of lignocellulosic wastes to improve ethanol and biogas production: a review. Int. J. Mol. Sci. 9, 1621-1651.

Várnai, A. Siika-aho, M. Viikari, L., 2010. Restriction of the enzymatic hydrolysis of steam-pretreated spruce by lignin and hemicellulose. Enzyme Microb. Technol. 46, 185-193.

Vasilakoglou, I., Dhima, K., Karagiannidis, N., Gatsis, T., 2011. Sweet sorghum productivity for biofuels under increased soil salinity and reduced irrigation. Field Crops Res. 120, 38-46.

Wu, X., Staggenborg, S., Propheter, J.L., Rooney, W.L., Yu, J., Wang, D., 2010. Features of sweet sorghum juice and their performance in ethanol fermentation. Ind. Crops Prod. 31, 164-170.

Yu, Q., Zhuang, X., Yuan, Z., Wang, Q., Qi, W., Wang, W., Zhang, Y., Xu, J., Xu, H., 2010. Two-step liquid hot water pretreatment of Eucalyptus grandis to enhance sugar recovery and enzymatic digestibility of cellulose. Bioresour. Technol. 101, 4895-4899.

Yu, Q., Zhuang, X., Yuan, Z., Wang, W., Qi, W., Wang, Q., Tan, X., 2011a. Step-change flow rate liquid hot water pretreatment of sweet sorghum bagasse for enhancement of total sugars recovery. Appl. Energy 88, 2472-2479.

Yu, Q., Zhuang, X., Yuan, Z., Qi, W., Wang, Q., Tan, X., 2011b. The effect of metal salts on the decomposition of sweet sorghum bagasse in flow-through liquid hot water. Bioresour. Technol. 102, 3445-3450.

Zhu, L., O’Dwyer, J.P., Chang, V.S., Granda, C.B., Holtzapple, M.T., 2008. Structural features affecting biomass enzymatic digestibility. Bioresour. Technol. 99, 3817-3828. 